\title{
Gold Nanoparticle-Polyaniline Composite Films for Glucose Sensing
}

\author{
Pratibha Pandey ${ }^{1,2}$, S. P. Singh ${ }^{1}$, Sunil K. Arya ${ }^{1,2}$, Anju Sharma ${ }^{1}$, \\ Monika Datta ${ }^{2}$, and Bansi D. Malhotra ${ }^{1, *}$ \\ ${ }^{1}$ Biomolecular Electronics and Conducting Polymer Research Group, National Physical Laboratory, \\ Dr. K. S. Krishnan Marg, New Delhi-110012, India \\ ${ }^{2}$ Department of Chemistry, University of Delhi, Delhi-110007, India
}

\begin{abstract}
Gold nanoparticles (AuNPs) have been self-assembled onto electrochemically deposited polyaniline (PANI) films on indium-tin-oxide (ITO) coated glass plates to fabricate glucose biosensor. The covalent immobilization of glucose oxidase (GOx) in the near vicinity of gold nanoparticles has been obtained using $\mathrm{N}$-ethyl- $\mathrm{N}^{\prime}$-(3-dimethylaminopropyl) carbodiimide (EDC)/N-hydroxysuccinimide (NHS), chemistry between amino groups of PANI and $\mathrm{COOH}$ groups of GOx. These AuNPs-PANI/ITO and GOx/AuNPs-PANI/ITO composite films have been characterized using Fourier transform infra red (FTIR) and cyclic voltammtery (CV) techniques, respectively. The fast electron transfer from the modified PANI surface to electrode has been indicating by the observed increase in amperometric response current of these GOx/AuNPs-PANI/ITO bioelectrodes. These GOx/AuNPsPANI/ITO bioelectrodes exhibit response time of $10 \mathrm{~s}$, linearity from 50 to $300 \mathrm{mg} / \mathrm{dl}$ and show value of apparent Michaelis-Menten constant $\left(K_{\mathrm{m}}^{\mathrm{app}}\right)$ of $2.2 \mathrm{mM}$.
\end{abstract}

Keywords: Gold Nanoparticles, Polyaniline, Composite, Glucose Sensing, Biosensor.

\section{INTRODUCTION}

Biosensors have recently attracted much attention because of their potential applications in clinical diagnostics, environmental monitoring, pharmaceuticals and food processing industries. ${ }^{1-3}$ For efficient operation of a biosensor, fast electron transfer between an electrode and a redox enzyme is very important. The chemical modification of enzymes with redox relay groups or the immobilization of enzymes in redox active polymers ${ }^{4-6}$ has been used to establish electrical communication between desired enzyme and electrode. However, unfavorable orientation of enzymes on an electrode surface or the adsorption of impurities onto a matrix results in sluggish electron transfer. ${ }^{7}$ Efforts are being made to enhance electron transfer from enzyme's active site to the electrode surface via use of mediators. In this context, use of a low molecular weight (soluble) mediator results in poor shelf life of biosensing electrode as it has the tendency to leach out and get diffused into the bulk solution. ${ }^{8}$ The leaching of mediator may lead to significant signal loss and affect the stability of the desired biosensor. Hence, search for new materials and methods for immobilizing given enzymes is

\footnotetext{
*Author to whom correspondence should be addressed.
}

presently an important subject to obtain stable biosensing electrodes. ${ }^{9,10}$

A variety of matrices have been used for immobilization of an enzyme to improve its activity and stability ${ }^{9-15}$ Nanoparticles, due to their unique physical and chemical properties, have emerged as promising materials and have been shown to play important roles in a wide range of areas such as electronics, catalysis, biomodeling, biolabeling, sensing, photonics and optoelectronics etc. ${ }^{16-18}$ Among the various nanomaterials, gold nanoparticles (AuNPs), exhibiting excellent catalytic and electron transfer properties, have been extensively used for modification of various electrodes and fabrication of different kinds of electrochemical biosensors. ${ }^{19}$ For electrode modification, AuNPs have been introduced in a desired matrix by different methods including covalent binding onto thiolterminated self assembled monolayers, ${ }^{20}$ utilizing amino group interaction with gold nanoaparticles, ${ }^{21}$ or by encapsulation into a porous sol-gel network. ${ }^{22}$ It is known that colloidal gold nanoparticles are non-toxic to a biological system and provide biocompatible environment for protein stabilization. ${ }^{19}$ And AuNPs adjacent to redox active centre of enzymes are found to act as an efficient nano-collector of electrons at desired electrodes. ${ }^{19}$ 
Hybrid polymer-nanoparticles systems are known to possess interesting electrical, optical and magnetic properties compared to those of the parent polymer and nanoparticles. ${ }^{23}$ Metal nanoparticles dispersed in polymeric matrices may result in increased stability, improved processability and enhanced catalytic properties. ${ }^{24-26}$ Among various conducting polymers, polyaniline (PANI) has been widely investigated due to its unique conduction mechanism and high environmental stability. ${ }^{27}$ The composite of AuNPs-PANI exhibits both charge transfer effect and charge transfer induced conductance switching suitable for memory device. ${ }^{28}$ However, composite of AuNPsPANI system for biosensing has not yet much investigated.

In the present manuscript we report the preparation and characterization of GOx/AuNPs-PANI composite deposited onto indium tin oxide coated glass substrate for estimation of glucose.

\section{MATERIALS AND METHODS}

\subsection{Chemicals and Reagents}

Hydrogen tetrachloroaurate (III) $\left(\mathrm{HAuCl}_{4} 3 \mathrm{H}_{2} \mathrm{O}\right)$, Nhydroxysuccinimide (NHS), N-ethyl-N'-(3-dimethylaminopropyl) carbodiimide (EDC), glucose oxidase (200 units/mg (U/mg)) and aniline monomer were purchased from Sigma (Aldrich). All chemicals were used without further purification. Deionized water was used for the preparation of aqueous solutions.

\subsection{Preparation of Gold Nanoparticles (AuNPs)}

Gold nanoparticles (AuNPs) solution was prepared using citrate reduction method. ${ }^{29}$ All glassware used was thoroughly rinsed with water and was dried prior to being used. A $20 \mathrm{ml}$ aqueous solution of $1 \mathrm{mM} \mathrm{HAuCl}{ }_{4}$ was brought to the boiling condition with stirring in a round bottomed flask fitted with a reflux condenser after which $38.8 \mathrm{mM}$ trisodium citrate solution was added rapidly to the solution. The solution was boiled for another $15 \mathrm{~min}$, during which its color changed from pale yellow to deep red. The solution was cooled to room temperature with continuous stirring. The AuNPs concentration estimated using Beer's law (extinction coefficient $\sim 10^{8} \mathrm{M}^{-1} \mathrm{~cm}^{-1}$ at $520 \mathrm{~nm}$ ) was found to be $\sim 24 \mathrm{nM}$. The particle size of AuNPs determined by Transmission Electron Microscopy (TEM) was found to be in the range $\sim 10-15 \mathrm{~nm}$ (Fig. 1).

\subsection{Solution Preparation}

The solution of glucose oxidase $(200 \mathrm{U} / \mathrm{ml})$ was freshly prepared in phosphate buffer $(50 \mathrm{mM}) \mathrm{pH}$ 7.0. The stock solution of D-glucose was prepared in Milli Q water and stored at $4{ }^{\circ} \mathrm{C}$. This stock solution was further diluted to prepare different concentrations of glucose solution.

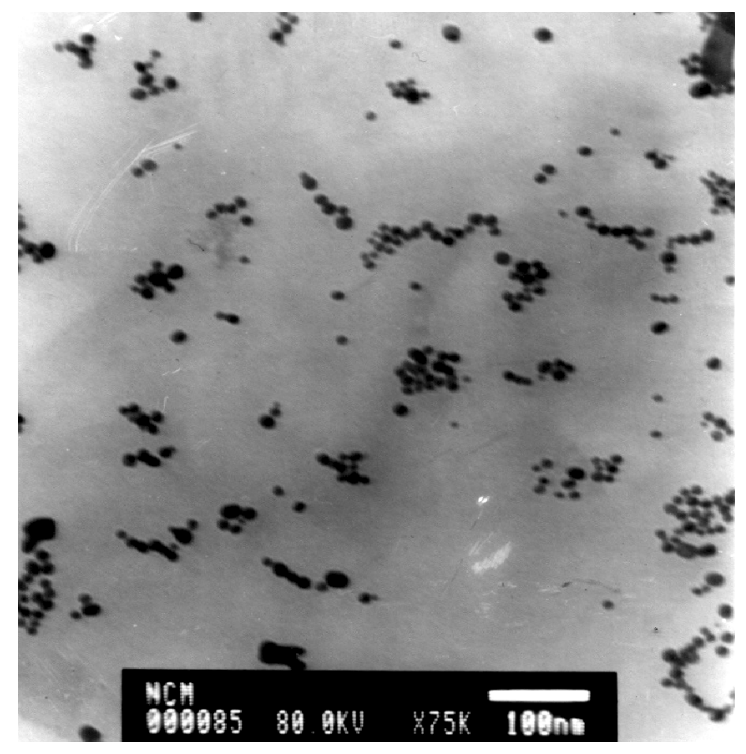

Fig. 1. TEM image of citrate capped gold nanoparticles.

\subsection{Fabrication of GOx/AuNPs-PANI/ITO Bioelectrodes}

The ITO glass plates were pre-cleaned with acetone, ethanol, and with copious amount of de-ionized water and were immersed into a solution of $\mathrm{H}_{2} \mathrm{O}_{2}: \mathrm{NH}_{4} \mathrm{OH}: \mathrm{H}_{2} \mathrm{O}$, 1:1:5 (v/v) for about $30 \mathrm{~min}$ at $80{ }^{\circ} \mathrm{C}$. These ITO glass plates were rinsed thoroughly with de-ionized water and dried in nitrogen atmosphere prior to electropolymerization of aniline $(0.1 \mathrm{M}$ aniline solution in $1 \mathrm{~N}$ $\mathrm{HCl})$. The electrochemical synthesis of polyaniline (PANI) film was carried out in a three-electrodes cell comprising of platinum ( $\mathrm{Pt}$ ) foil as a counter electrode, $\mathrm{Ag} / \mathrm{AgCl}$ as a reference electrode and ITO coated glass plate as the working electrode by chrono-potentiometric technique using current of $200 \mu \mathrm{A}$ for about $600 \mathrm{~s}$. These PANI/ITO electrodes were dipped into the solution of $\sim 24 \mathrm{nM}$ of gold nanoparticles (AuNPs) overnight for self-assembly of AuNPs in PANI film. The $-\mathrm{NH}^{+}-$groups of PANI matrix were utilized for strong electrostatic interaction with gold nanoparticles and $-\mathrm{NH}_{2}$ groups for covalent immobilization of enzyme. The enzyme (glucose oxidase; GOx) was covalently immobilized onto AuNPs/PANI/ITO composite film using EDC/NHS chemistry. ${ }^{30}$ The prepared enzyme modified electrode (GOx/AuNPs-PANI/ITO) was washed thoroughly with phosphate buffer $(50 \mathrm{mM}, \mathrm{pH}$ 7.0) containing $0.9 \% \mathrm{NaCl}$ to remove any unbound enzymes and was stored at $4{ }^{\circ} \mathrm{C}$ when not in use. Scheme 1 shows various steps relating to the fabrication of GOx/AuNPsPANI/ITO bioelectrodes.

\subsection{Characterization}

The FTIR spectra of AuNPs-PANI/ITO electrode and GOx/AuNPs-PANI/ITO bioelectrode were recorded using 


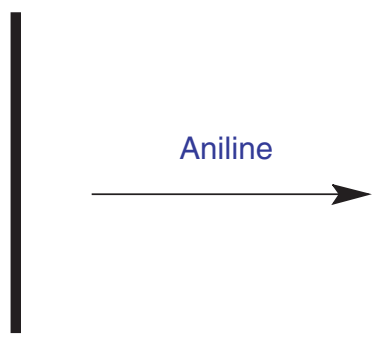

ITO

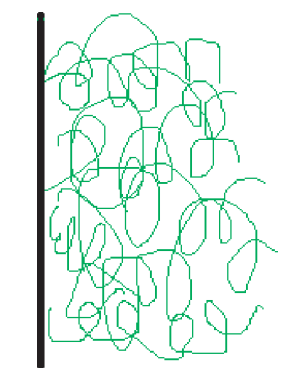

PANI/ITO
(AuNPs)
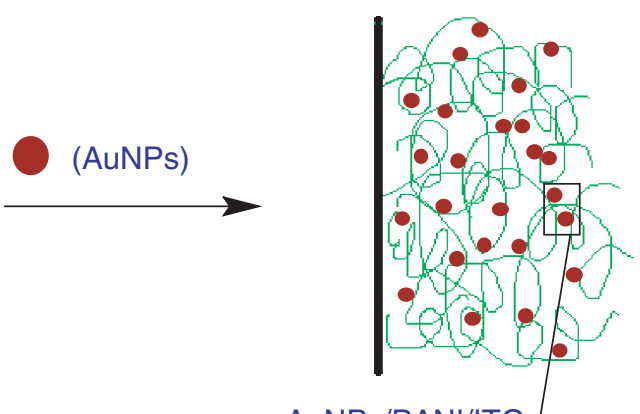

AuNPs/PANI/ITO

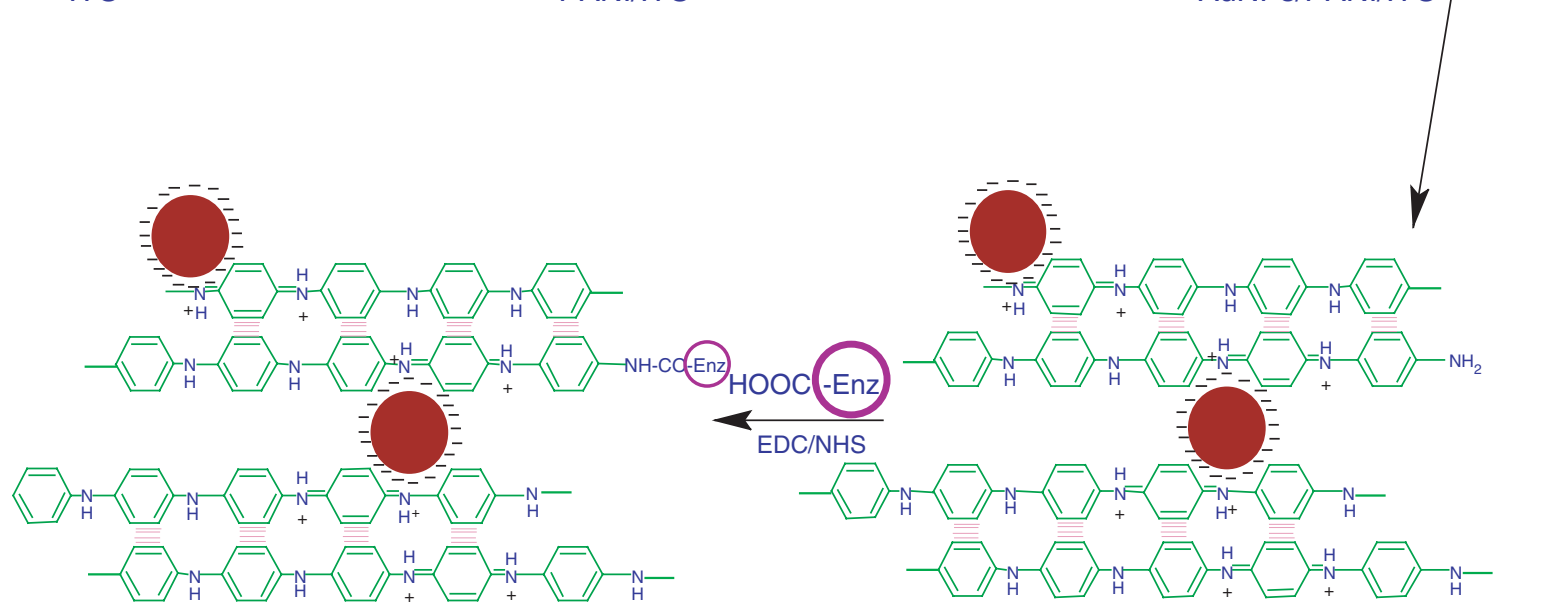

Scheme 1. Schematic of the fabrication of the GOx/AuNPs-PANI/ITO bioelectrode.

a Perkin-Elmer (Spectrum BXII) spectrometer to check binding of gold nanoparticles and enzyme with PANI/ITO film, respectively. The enzyme activity measurements on AuNPs-PANI/ITO films were carried out using Linear Sweep Voltametry (LSV). The cyclic voltammetric (CV) and LSV studies were conducted an Autolab Potentiostat/Galvanostat (Eco Chemie, Netherlands) using a three-electrodes cell with $\mathrm{Ag} / \mathrm{AgCl}$ electrode as a reference electrode and $\mathrm{Pt}$ foil as a counter electrode in a $10 \mathrm{ml}$ of phosphate buffer saline (PBS) solution (50 mM, pH 7.0, $0.9 \% \mathrm{NaCl}$ ) with the scan rate of $0.05 \mathrm{~V} / \mathrm{s}$.

\section{RESULTS AND DISCUSSION}

\subsection{Fourier Transform Infra Red (FTIR) Spectroscopy Studies}

Figure 2 shows the FTIR spectra obtained for PANI/ITO (Curve a), AuNPs-PANI/ITO (Curve b) and GOx/AuNPsPANI/ITO (Curve c) films, respectively. The presence of a sharp and intense band at $3186 \mathrm{~cm}^{-1}$ and $3434 \mathrm{~cm}^{-1}$ is due to $-\mathrm{NH}$ stretching vibration. The incorporation of gold nanoparticles results in change in the shape and frequencies of the bands in this region, indicating that amino groups are involved in the attachment of AuNPs with PANI film. The shift in the peak of $\mathrm{C}^{-} \mathrm{N}^{+}$from 1247 (curve a) to 1259 (curve b) $\mathrm{cm}^{-1}$ is attributed to the attachment of AuNPs to the backbone of polyaniline. The appearance of intense and sharp absorption bands at
$1640 \mathrm{~cm}^{-1}$ in the FTIR spectra of GOx/AuNPs-PANI/ITO is attributed to the formation of amide bond after immobilization of GOx on the AuNPs-PANI/ITO electrode (Fig. 2(c)). The band in $1200-1300 \mathrm{~cm}^{-1}$ region is assigned to the combination of $\mathrm{N}-\mathrm{H}$ bending and $\mathrm{C}-\mathrm{N}$ stretching. The $463 \mathrm{~cm}^{-1}$ peak seen in the IR spectra of AuNPs-PANI/ITO electrode and GOx/AuNPs-PANI/ITO bioelectrode may be assigned to the formation of composite indicating incorporation of gold nanoparticles in the polymer matrix.

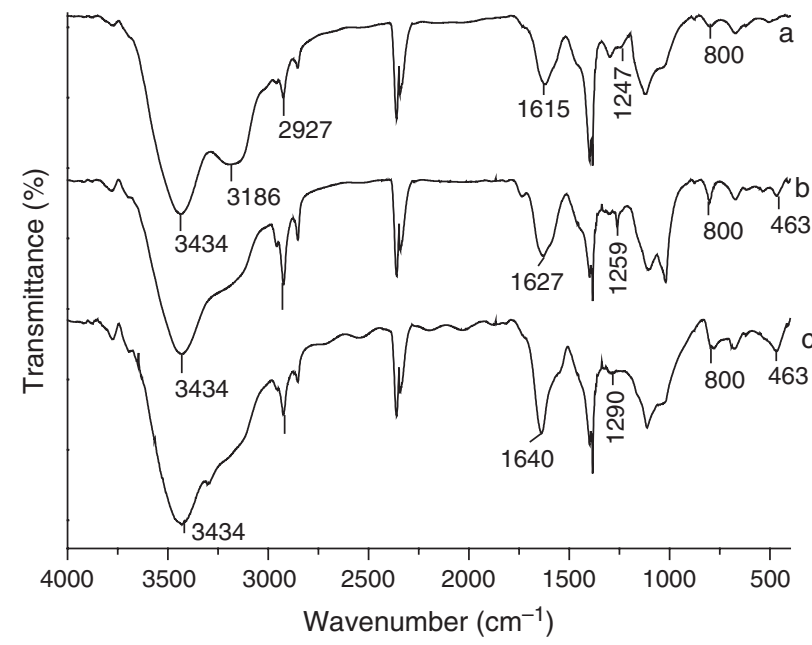

Fig. 2. FTIR spectra of (a) PANI film, (b) AuNPs-PANI, (c) GOx/ AuNPs-PANI film on ITO surface. 
Table I. Characteristics of different glucose biosensors based on GOx enzyme immobilized on various nanomaterials based electrodes.

\begin{tabular}{|c|c|c|c|c|c|c|}
\hline S.No. & Immobilization Matrix & Method of Immobilization & Detection range $(\mathrm{mM})$ & $K_{\mathrm{m}}(\mathrm{mM})$ & Shelf life & Reference \\
\hline 1 & Titania sol-gel membrane & Entrapment & $0.07-15$ & 6.38 & 80 days & 31 \\
\hline 2 & Silica nanoparticles & Covalent & Upto 8 & & & 32 \\
\hline 3 & Polypyrrole/corbon nanotubes & Entrapment & Upto 4 & & & 33 \\
\hline 4 & Chitosan/AuNPs & Covalent & $5.0 \times 10^{-2}-3$ & & & 34 \\
\hline 5 & $\mathrm{Au}$ NP/CPE & Electrostatic & $0.04-0.28$ & & & 35 \\
\hline 6 & $\mathrm{ZrO} 2 /$ chitosan film & Entrapment & $0.125-9.5$ & 3.45 & 30 days & 36 \\
\hline 7 & Magnetite nanoparticles & Covalent & Upto 20 & 6.8 & 90 days & 37 \\
\hline 8 & PANI/AuNPs/ITO & Covalent & $2.7-16$ & 2.2 & 11 weeks & Present work \\
\hline
\end{tabular}

\subsection{Cyclic Voltammetric Studies}

Figure 3 shows the cyclic voltammogrammes obtained for PANI/ITO (Curve a), PANI-AuNPs/ITO (Curve b) and GOx/AuNPs-PANI/ITO (Curve c) electrodes, respectively with scan rate of $0.05 \mathrm{~V} / \mathrm{s}$ in PBS buffer $(\mathrm{pH} 7.0)$. In the cyclic voltammogram of PANI/ITO electrode (Fig. 3(a)) the observed oxidation peak at $0.17 \mathrm{~V}$ peak corresponds to the oxidation of PANI and arises due to polaron formation. The broadness in this peak indicating slow transfer of electrons may perhaps be attributed either to the amorphous behaviour of PANI or to the diffusion of generated electrons into the polyaniline matrix. In the cyclic voltammogramme of AuNPs-PANI/ITO electrode (Fig. 3(b)), the oxidation current increases and the peak becomes sharper at the higher oxidation potential. The sharpness of oxidation peak suggests reduction in the diffusion of generated electrons and enhanced electron transfer from the surface to the PANI-AuNPs/ITO electrode. The formation of AuNPs-PANI composite has been known to result in fast charge transfer effect and the charge transfer induced conductance switching due to partial transfer of electron clouds at the conjugate $\mathrm{C}=\mathrm{N}$ bond to gold nanoparticles via ionic interactions between negatively charged citrate capped gold nanoparticles and positively charged species of PANI. ${ }^{28}$ The observed shift in oxidation peak potential in the present studies is attributed to such transfer

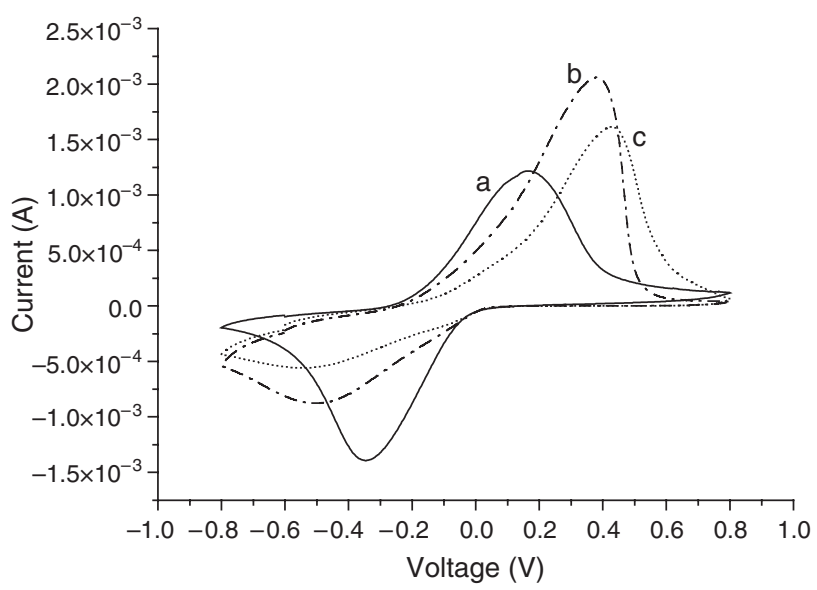

Fig. 3. Cyclic voltammogrammes for (a) PANI/ITO film, (b) AuNPsPANI/ITO electrode, (c) GOx/AuNPs-PANI/ITO bioelectrode. of electron cloud from PANI to gold nanoparticles and require higher energy to remove an electron from the PANI film to form polarons. The cyclic voltammogramme (Fig. 3(c)) of GOx/AuNPs-PANI/ITO electrode shows decrease in the oxidation peak current compared to that of the AuNPs-PANI/ITO electrode and is attributed to the non-conducting nature of enzymes. The observed changes in the behaviour of oxidation peaks for the PANI/ITO, AuNPs-PANI/ITO and GOx/AuNPs-PANI/ITO electrodes indicate attachment of AuNPs with PANI and immobilization of GOx enzyme onto the composite.

\subsection{Enzyme (GOx) Activity Studies}

Linear Sweep Voltametry (LSV) in PBS (50 mM, pH 7.0, $\mathrm{NaCl} 0.9 \%$ ) in the range of 0.1 to $0.8 \mathrm{~V}$ with scan rate of $0.05 \mathrm{~V} / \mathrm{s}$ has been used to investigate the enzymatic (GOx) activity. The observed current around $\sim 0.5 \mathrm{~V}$ due to the oxidation of $\mathrm{H}_{2} \mathrm{O}_{2}$ generated as a result of enzyme substrate reaction (Eq. (1) and (2)) in LSV scan has been monitored and is plotted (Fig 4(a)). The magnitude of the current is found to increase with increase in the glucose concentration (Fig. 4(a)). Figure 4(a) shows the variation in current measured at a fixed voltage of $0.5 \mathrm{~V}$ as a function of glucose concentration $(50-300 \mathrm{mg} / \mathrm{dl})$. The response time of the glucose biosensing electrode is found to be relatively fast $(\sim 10 \mathrm{~s})$ and is attributed to faster electron communication in the AuNPs-PANI/ITO electrode.

$$
\begin{array}{r}
\text { Glucose }+\mathrm{O}_{2} \stackrel{\text { GOx/PANI/AuNPs/TTO }}{\longrightarrow} \text { Gluconic acid }+\mathrm{H}_{2} \mathrm{O}_{2} \\
\mathrm{H}_{2} \mathrm{O}_{2} \stackrel{\text { Electrochemical oxidation }}{\longrightarrow} 2 \mathrm{H}^{+}+\mathrm{O}_{2}+2 \mathrm{e}^{-}
\end{array}
$$

The results of triplicate sets indicated by error bars reveal the reproducibility of the GOx/AuNPs-PANI/ITO bioelectrode. To reveal the affinity of enzyme for its substrate, enzyme substrate kinetics parameter i.e., Michaelis-Menten constant $\left(K_{\mathrm{m}}\right)$ for the GOx/AuNPsPANI/ITO bioelectrode has been estimated by Hanes plot (Fig. 4(b)). The value of the apparent $K_{\mathrm{m}}$ for enzyme GOx/AuNPs-PANI/ITO bioelectrode is found to be relatively lower $(2.2 \mathrm{mM}(39.64 \mathrm{mg} / \mathrm{dl}))$ than reported by other researchers (Table 1), indicating high affinity of 

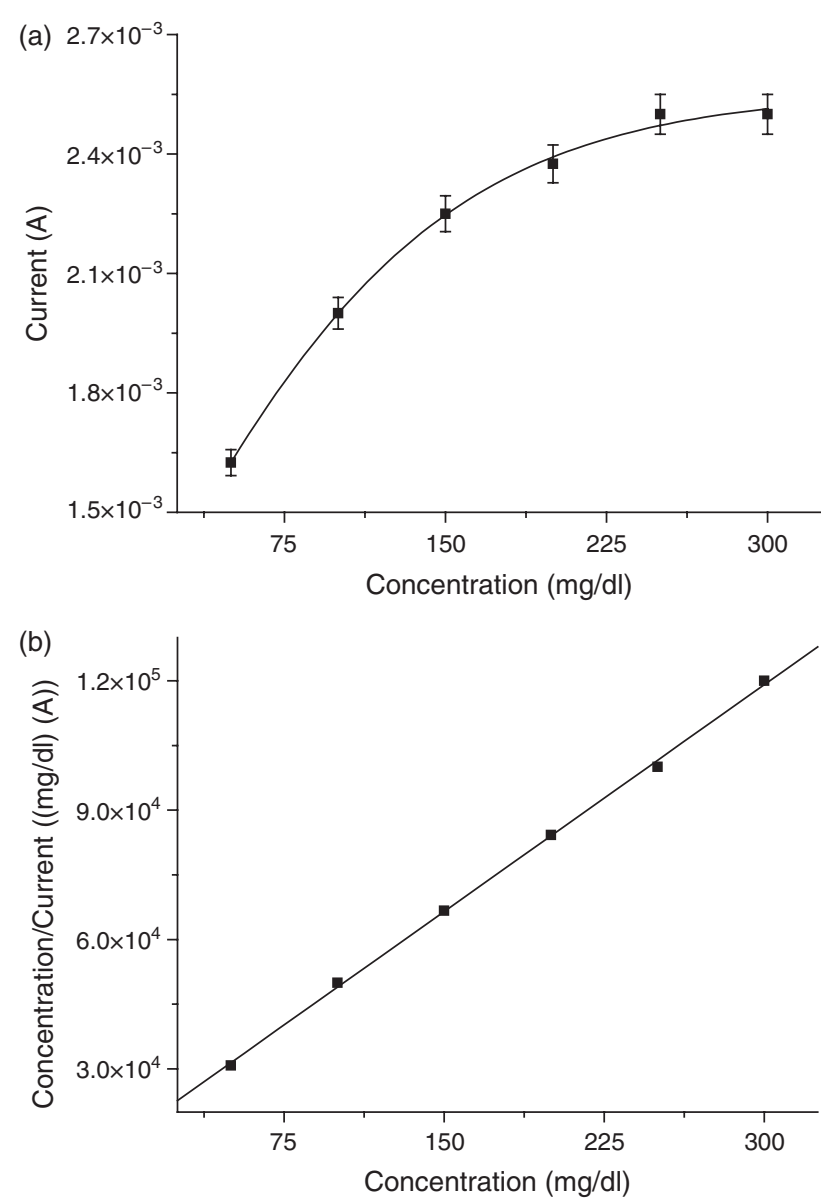

Fig. 4. (a) Current response of GOx/AuNPs-PANI/ITO bioelectrode as a function of glucose concentration, (b) Hanes plot of GOx/AuNPsPANI/ITO bioelectrode as a function of glucose concentration.

GOx/AuNPs-PANI/ITO bioelectrode for its substrate (glucose). Surface morphology and nature of immobilization matrix play important role in enhancing the activity of enzyme which in turn reflects favorable conformational change in enzyme's active site after immobilization. The observed higher affinity with enhanced activity of GOx on AuNPs-PANI/ITO electrode suggests efficient GOx loading and favorable conformational change of GOx enzyme provided by the microenvironment of AuNPs polyaniline composite films.

\subsection{Effect of pH and Interferents on GOx/AuNPs-PANI/ITO Bioelectrode}

To find the working range of $\mathrm{pH}$ for GOx/AuNPsPANI/ITO bioelectrode, GOx modified electrode has been investigated in the $\mathrm{pH}$ range of $6.0-8.0$ at $30{ }^{\circ} \mathrm{C}$. The behaviour of GOx/AuNPs-PANI/ITO bioelectrode at various $\mathrm{pH}$ (data not shown) indicates that the GOx/AuNPsPANI/ITO bioelectrode is most active near $\mathrm{pH}$ 6.5.

Effect of interferents such as ascorbic acid $(0.05 \mathrm{mM})$, uric acid $(0.1 \mathrm{mM})$, lactic acid $(0.5 \mathrm{mM})$, sodium pyruvate $(5 \mathrm{mM})$ and urea $(1 \mathrm{mM})$ on glucose measurement has

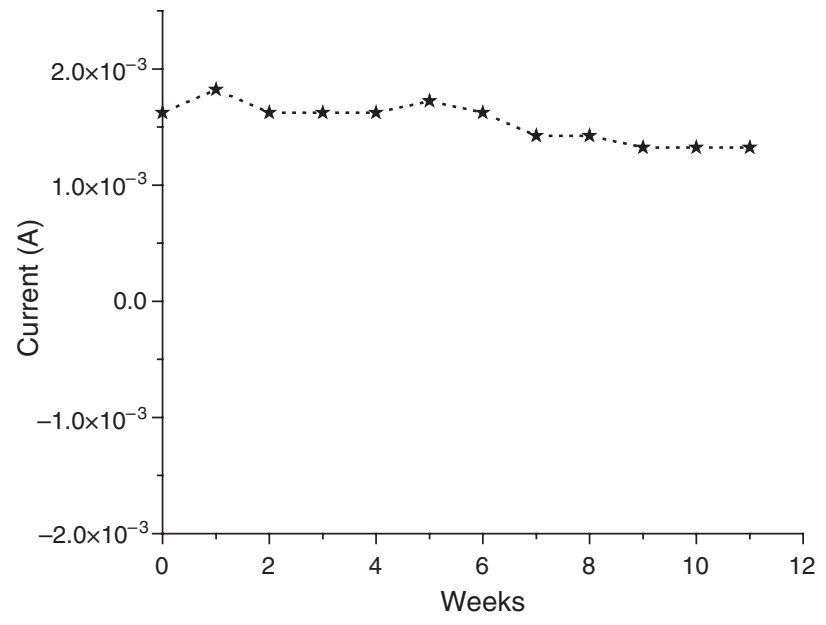

Fig. 5. Shelf life of GOx/AuNPs-PANI/ITO bioelectrode with time.

been studied by mixing interferents respectively with glucose $(50 \mathrm{mg} / \mathrm{dl})$ in $1: 1$ ratio and monitoring the peak at $0.5 \mathrm{~V}$ in the $\mathrm{CV}$ spectra under similar conditions as used for samples without interferents. The results suggest that presence of urea and sodium pyruvate do not exhibit any interference whereas lactic acid shows $\sim 5 \%$ of interference effect. The GOx/AuNPs-PANI/ITO bioelectrode is found to be susceptible towards the presence of ascorbic acid and uric acid with interference of more than $15 \%$.

\subsection{Shelf Life of GOx/AuNPs-PANI/ITO Bioelectrode}

To investigate the stability of enzyme GOx/AuNPsPANI/ITO bioelectrode, CV experiments have been carried out at regular interval of a week for about 11 weeks with the glucose concentration of $50 \mathrm{mg} / \mathrm{dl}$ and temperature of $30{ }^{\circ} \mathrm{C}$. Figure 5 shows the stability in terms of current indicating that GOx/AuNPs-PANI/ITO bioelectrode retains more than $85 \%$ of the GOx activity even after 11 weeks. The excellent stability and shelf life of enzyme can be attributed to the self-assembled gold nanoparticles on PANI film providing the desired biocompatible environment to the immobilized enzyme (GOx).

\section{CONCLUSIONS}

It has been shown that the matrix formed by self organization of gold nanoparticle on electrochemically polymerized polyaniline film onto indium-tin-oxide glass can be utilized to fabricate glucose biosensor. For self organization of AuNPs on PANI film electrostatic interaction between amine group of PANI and gold nanoparticles has been exploited. Amino groups of PANI have been utilized for the covalent immobilization of glucose oxidase in the near vicinity of AuNPs. The GOx/PANI-AuNPs/ITO bioelectrode based glucose biosensor shows fast response time of $10 \mathrm{~s}$ and detection range of $50-300 \mathrm{mg} / \mathrm{dl}$. Enhanced activity of the immobilized enzyme (GOx) is reflected by 
smaller $K_{\mathrm{m}}$ value of $2.2 \mathrm{mM}$. Efforts should be made to utilize this matrix for other biosensors.

Acknowledgments: We are grateful to Dr. Vikram Kumar, Director NPL, New Delhi, India, for his interest in this work. We thank Dr. Sukhvir Singh for TEM studies. Pratibha Pandey is grateful to the University Grants Commission (UGC), India, for the award of a Senior Research Fellowship. Financial support received under the CSIR network project, DBT sponsored projects (BT/PR7667/MED/14/1057/2006) and DST project (ID/SEN/SI/03) is acknowledged.

\section{References and Notes}

1. X. Luo, A. Morrin, J. A. Killard, and R. M. Smyth, Electroanalysis 18,319 (2006).

2. B. D. Malhotra, A. Chaubey, and S. P. Singh, Anal. Chim. Acta 578, 59 (2006).

3. C. A. Grimes, E. Dickey, and M. Pishko (Eds.), Encyclopedia of Sensors, American Scientific Publishers, Los Angeles, CA (2006), Vol. 1-10.

4. Y. Degani and A. Heller, J. Phys. Chem. 91, 1285 (1987).

5. W. Schuhmann, T. J. Ohara, H. L. Schmidt, and A. Heller, J. Am. Chem. Soc. 113, 1394 (1991).

6. C. Kranz, H. Wholschlager, H. L. Schmidt, and W. Schuhmann, Electroanalysis 10, 546 (1998).

7. Q. Xu, C. Mao, N. N. Liu, J. J. Zhu, and J. Sheng, Biosens. Bioelectron. 22, 768 (2006).

8. J. Z. Xu, J. J. Zhu, Q. Wu, Z. Hu, and H. Y. Chen, Electroanalysis 15,21 (2003).

9. Y. Xiao, H. X. Ju, and H. Y. Chen, Anal. Chim. Acta 391, 73 (1999).

10. A. Ramanavicius, K. Habermuller, E. Csoregi, V. Laurinavicius, and W. Schuhmann, Anal. Chem. 71, 3581 (1999).

11. H. Yang, T. D. Chung, Y. T. Kim, C. A. Choi, C. H. Jun, and H. C. Kim, Biosens. Bioelectron. 17, 251 (2002).

12. Z. Dai, S. Liu, H. X. Ju, and H. Y. Chen, Biosens. Bioelectron. 19, 861 (2004)

13. H. H. Liu, Z. Q. Tian, and Z. X. Lu, Biosens. Bioelectron. 20, 294 (2004).

14. X. Zhong, R. Yuan, Y. Chai, Y. Liu, J. Dai, and D. Tang, Sens. Actuators B 104, 191 (2004).
15. Y. Xian, Y. Hu, F. Liu, Y. Xian, H. Wang, and L. Jin, Biosens. Bioelectron. 21, 1996 (2006).

16. M. J. Feldstein, C. D. Keating, Y. H. Liau, M. J. Natan, and N. F. Scherer, J. Am. Chem. Soc. 119, 6638 (1997).

17. K. Fukumi, A. Chayahara, K. Kadono, T. Sakaguchi, Y. Horino, M. Miya, K. Fujii, J. Hayakawa, and M. Satou, J. Appl. Phys. 75, 3075 (1994).

18. R. F. Hagland, L. Yang, R. H. Magruder, J. E. Wittig, K. Becker, and R. A. Zuhr, Opt. Lett. 18, 373 (1993).

19. M. Daniel and D. Astruc, Chem. Rev. 104, 293 (2004).

20. Y. Xiao, F. Patolsky, E. Katz, J. F. Hainfeld, and I. Willner, Science 299, 1877 (2003).

21. J. J. Feng, J. J. Xu, and H. Y. Chen, Biosens. Bioelectron. 22, 1618 (2007).

22. J. Jia, B. Wang, A. Wu, G. Cheng, Z. Li, and S. Dong, Anal. Chem. 74, 2217 (2002).

23. L. Guo, S. C. Yang, P. Yu, J. Wang, W. Ge, and G. K. L. Wong, Chem. Mater. 12, 2268 (2002).

24. R. M. Crooks, M. L. Sun, V. Chechik and L. K. Yeung, Acc. Chem. Res. 34, 181 (2001).

25. N. Krasteva, I. Besnard, B. Guse, R. E. Bauer, K. Mullen, A. Yasuda and T. Vossmeyer, Nano Lett. 2, 555 (2002).

26. R. Shenhar, T. B. Norsten, and V. M. Rotello, Adv. Mater. 17, 657 (2005).

27. Z. M. Tahir, E. C. Alocilja, and D. L. Grooms, Biosens. Bioelectron. 20, 1690 (2005).

28. R. J. Tseng, C. O. Baker, J. Huang, R. B. Kaner, J. Ouyang, and Y. Yang, Appl. Phys. Lett. 90, 053101 (2007).

29. J. Turkevitch, P. C. Stevenson, and J. Hillier, Discuss Faraday Soc. 11, 55 (1951).

30. S. K. Arya, A. K. Prusty, S. P. Singh, P. R. Solanki, M. K. Pandey, M. Datta, and B. D. Malhotra, Anal. Biochem. 363, 210 (2007).

31. T. J. Rajgopalan and R. Heller, Anal. Chem. 66, 2451 (1994).

32. Y. Sun, F. Yan, W. Yang, and C. Sun, Biomaterials 27, 4042 (2006).

33. C. Y. Tsai, C. S. Li, and W. S. Liao, Biosens. Bioelectron. 22, 495 (2006).

34. Y. Du, X. L. Luo, J. J. Xu, and H. Y. Chen, Bioelectrochemistry 70, 342 (2007).

35. W. Yang, J. Wang, S. Zhao, Y. Sun, and C. Sun, Electrochem. Commun. 8, 665 (2006).

36. Y. H. Yang, H. F. Yang, M. H. Yang, Y. L. Liu, G. L. Shen, and R. Q. Yu, Anal. Chim. Acta 525, 213 (2004).

37. M. L. Rossi, A. D. Quach, and Z. Rosenzweig, Anal. Bioanal. Chem. 380, 606 (2004).

Received: xx Xxxx xxxx. Revised/Accepted: xx Xxxx xxxx. 